\title{
Research on College Students' Professional Quality and Cultivation of Innovative and Entrepreneurial Talents
}

\author{
Ke Tang ${ }^{1,2,3}$, Mengxue Zuo ${ }^{1, *}$, Min Tian ${ }^{1,2,3}$
}

${ }^{1}$ School of Economics and Management, Xi'an Technological University, Xi'an 710021, China

${ }^{2}$ Soft Science Base for Ordnance Industry Innovation\&Dvelopment in Shaanxi Province, Xi'an 710021, China ${ }^{3}$ Civil- Military Integration Science and Technology Innovation Research Center of Shaanxi's Colleges and Universities, Xi'an 710021, China

*Corresponding author. Email: 1619980962@qq.com

\begin{abstract}
Through the cultivation of college students' professional consciousness, professional knowledge and professional ability, we can improve their professional accomplishment of college students, make them meet the requirements of employers, and improve the employment rate of college students. Through the cultivation of college students' psychological quality and innovative ability, they can become innovative people with the potential of entrepreneurship.
\end{abstract}

Keywords: Professional accomplishment, Employability, Innovative consciousness, Entrepreneurial potential.

\section{大学生职业素养及创新创业型人才培养研究}

$$
\text { 唐可 } 1,2,3 \text { ，左孟雪 } 1{ }^{*} \text { ，田敏 } 1,2,3
$$

\footnotetext{
${ }^{1}$ 西安工业大学经济管理学院, 陕西 西安 710021

2 陕西省兵工科技创新发展软科学研究基地, 陕西 西安 710021

3 陕西高校军民融合科技创新研究中心，陕西 西安 710021

“通讯作者. 邮箱: 1619980962@qq.com
}

中文摘要

通过对大学生职业意识、职业知识、职业能力的培养，提高大学生的职业素养，使之适合用人单位的要求，提 高大学生的就业率。通过对大学生心理素质和创新能力的培养, 使之成为创新型人, 具备创业的潜质。

关键词：职业素养，就敜能力，创新意识，创业潜质

\section{1. 引言}

当代大学生尤其城市出生的基本都是独生子女, 由于长期在家庭的爱护、保护下生活，养成了很多不 良习惯, 难以适应社会的要求, 又遇到大学扩招带来
的就业难问题，很多大学生无所是从，有的干脆重新 回到父母的怀抱，靠啃老生活。从学生的实习单位访 谈得到的信息, 普遍反映现在的大学生职业素养低, 沟通能力差, 不能适应用人单位的要求。有些单位反 映 “我们缺人，而且正在招人，有适合的大学生我们 
肯定要, 但是能达到我们要求的不多”。这个说明了 我们对大学生的培养出现了问题, 与社会和企业的人 才需求出现了脱节, 只重视了学生专业知识的培养, 忽略了专业技能的培养, 尤其是缺乏职业素养的培 养。这就要求我们在大学里就开始对大学生的职业素 养进行培养, 养成一个良好的学习、生活、工作习惯。 “师者, 传道、授业、解惑者也”, 我们不能简单的 停留在授业这个层面, 而是要全方位的进行。而且这 方面的工作不能等到学生大四快找工作了才突击进 行, 而是从大学生进入大学的第一天就开始, 经过四 年不间断的培养, 那么职业素养已经得到培养的学生 一定会适应社会和用人单位的需求, 他们的就业不会 再难。职业素养的培养包括: 职业意识, 职业知识、 职业能力三个方面的培养。

\section{2. 大学生职业意识培养}

培养目标是使学生不仅掌握知识与技能, 同时具 备职业意识所要求的核心内容: 公平正直、敬业爱岗、 团结协作、诚信负责、自律、自信、自强不息。从大 一入学开始, 这项培养工作就可以有计划的开展。在 入学教育的时候, 这些方面的内容都要给学生讲到, 包括一些名人传记、成功案例都要推荐给学生课外阅 读。而且这方面的工作要制度化, 例如每周固定一天 下午, 由辅导员或班主任老师专门进行这方面学习和 讲座。有时也可以在辅导员、班主任老师的主持下, 邀请企业或其他社会人事来给学生做这方面的报告, 学校从经费上给与支持。在学校的组织下, 鼓励学生 参加各种班级、年级或者院系活动, 让学生真正参与 进去, 在活动中加强互动、协作。这些方面也可以制 度化, 例如每月固定一天在辅导员、班主任的带领下 参加社会活动, 尤其是公益活动, 学生必须参加, 不 得缺席, 学校给与一定经费支持, 学生在这些活动中, 学习到团结、协作、互助、吃苦耐劳等精神。对学生 的日常生活进行管理, 例如对学生宿舍的 $6 \mathrm{~s}$ 管理, 让学生学会整理、整顿、清扫、清洁、素养、安全的 准则, 养成良好的生活习惯, 这些习惯带到工作中, 就是良好的工作习惯。学生在宿舍里可以分工互相管 理，例如有人负责管卫生，监督大家搞好宿舍和个人 卫生; 有人负责管学习, 监督大家按时到课, 按时自 习; 有人负责管理生活, 监督大家打开水、洗碗等。 在这些日常小事的管理中, 学生自然而然的学习到了 公平、正直、负责、自律等好的品德和管理能力。这 些工作长期坚持下去, 潜移默化, 到学生参加工作的 时候, 职业意识已经培养出来了, 到工作单位适应很 快，很容易的就融入集体、融入工作。

\section{3. 大学生职业知识培养}

职业知识可以分为专业知识和通用知识, 专业知 识指劳动者具备从事某项职业活动所要求的特殊知 识和技能, 通用知识包括经济管理知识、社会文化知 识。对大学生职业知识的培养体现课程设计中减少专 业必修课, 拓宽专业基础, 增加经济、管理、人文、
社科、艺术等选修课程门类和课时, 突出能力培养, 适应市场经济的需求。经济、管理课程的设置注重以 市场需求为导向, 树立 “大管理” 理念, 通过融合和 创新管理类学科知识, 满足市场经济浪潮中快速崛起 的各种企业的需求。培养学生应对市场经济条件下工 商企业经营实践中所需要的发现问题、捕捉商机、开 拓进取、团结协作、提升业绩等市场意识和创新精神。 教学内容应以实用性知识为主, 强调针对性, 争取做 到学即能用, 适当补充企业管理实务中新出现问题的 研讨专题课, 使毕业生具有更强的适应能力。

\section{4. 大学生职业能力培养}

\section{1. 沟通能力培养}

现代复合型人才要求有良好的沟通能力, 理解并 真正领悟对方的真实意图, 并把自己意义阐述清楚, 是建立良好合作关系的基础。“听” 和 “说” 同样 重要, 要达到好的沟通效果, 首先得学会 “倾听”。 上课就是教师和学生的沟通过程, 学生在这个过程里 要学会 “倾听”。首先要注意力集中, 专注教师的一 举一动, 跟着教师的思维。学会和教师 “互动”, 对 教师的口头语言和肢体语言都要给与适当的回应。学 会抓住教师讲解的重点, 并记录下来形成笔记。这也 是一种职业能力的培养, 如果不能有效的记录教师的 讲话要点, 以后工作了怎么去理解领导的意图和要点 呢? 实际上, 掌握了记录要点, 一是备忘, 好复习。 二是抓要点并记录本身就是一种能力, 而且这种能力 是很多职业必备的。比如办公室主任、甚至总经理助 理等, 都需要这种能力。在练好 “听” 的基础上, 就 要加强 “说” 的锻炼和练习。当众表达自己的想法, 很多时候会面临很大的心理压力。教师必须帮助大学 生克服这种压力, 让大学生从敢于表达到善于表达。 首先, 教师的风格应该诙谐、幽默, 这样课堂的氛围 会比较好, 大学生在这种氛围下心态得到了放松, 不 会那么紧张。第二, 教师要善于鼓励和表扬学生, 只 要敢站起来回答问题, 不管对错都给学生一定的平时 分。第三, 多设开放型问题, 让学生自由发挥, 各抒 己见。甚至可以提前留问题, 让大学生下去以团队的 形式准备。学生准备的越充分, 胆子就会越大, 越敢 当众表达自己。如果就某个问题, 设正反两个答案。 让学生分组辩论，效果会更好。

\section{2. 执行能力培养}

锻炼执行能力的前提, 是让学生学会服从。在团 队里面, 民主和集中都存在, 关键是让学生知道什么 时候民主，什么时候集中一 团队决策以前讲民主， 该说的话说透, 该表达的意见畅所欲言, 一旦定下来, 就必须执行。理解的要执行, 不理解的也要执行, 在 执行中加强理解, 这就是纪律, 这就是执行力。服从 是军人的天职, 军队铁的纪律也是军队战斗力的体 现。自信心对于执行力也是非常重要的, 很多事情本 来有能力做到, 但是因为缺乏自信没有勇气去做, 使 
得很多人错失了宝贵的机会。就像很多大学生在实习 推销员的时候，不敢去敲顾客的门。其实这也是一种 心理障碍, 老师一种要鼓励学生去突破。可以组织学 生参加拓展训练, 去挑战自己的心理关。拓展训练是 美国训练海军陆战队执行力的方法, 源自于二战时 期。当时美国有艘潜艇出事故, 很多船员依靠救生圈 漂浮在海面上, 等第二天救援人员赶到时, 发现已经 有很多人遇难。事后, 军方对幸存者进行了调查, 结 果非常出人意料, 幸运者并不是那些最强壮的人, 而 是求生欲望最强烈的, 最自信的人。那些最强壮的人 不是死于饥饿, 而是死于绝望, 通过拓展训练可以培 养学生执行任务的自信、胆略和勇气。胆大、心细、 脸皮厚, 是现代开拓性人才的必要条件, 胆大指的有 勇气、有魄力; 心细指的是严谨、一丝不苟; 脸皮厚 指的是指坚强、抗压能力强、抗屈辱能力强。具备了 这些心理素质的人，执行力就得到基本保障。

\section{3. 创新能力培养}

中国有几千年的教育发展史，其中有一些简单而 朴素的创新能力培养的思想和方法。例如, 两千多年 前, 在《道德经》中老子提出 “天下万物生于有, 有生于无” 的创新思维; 孔子提出要 “因材施教” 以 及 “不愤不启, 不悱不发; 举一隅而不以三隅反, 则 不复也”的创新思想。

这说明学生创新的思维就是由课堂上举一反三开 始的, 有了一个解决问题的方法是不够的, 还要试图 找出另外的方法。所以给学生标准答案的方式严重的 限制了学生的思维, 破坏了学生的创新能力, 虽然标 准化考试能够提高阅卷效率, 也看似公平, 其实弊大 于利。我们提倡不设标准答案, 让学生空间自由发挥, 只要能运用所学知识自圆其说, 就给高分。长期用此 方法培养, 学生就会打破应试教育带来的思想僵化问 题, 敢用所学的所有知识解决问题, 而不是用某门课 的知识。或许悟性强的学生遇到苹果落到头上, 就像 牛顿一样灵感一闪, 万有引力公式就创造出来了。还 要培养学生敢为天下先和敢于承担责任的精神, 创新 的难度往往不是创新本身, 而是创新带来的风险。只 有敢想、敢干, 不惧艰难、不怕失败, 创新才会成为 可能。如果 100 种方法里有且只有一种能够成功, 那 么失败一次, 下一次成功的可能性就大一次。这是是 个简单的概率问题, 第一次成功的可能性是 $1 \%$, 第 二次就是 $1 / 99$, 第三次是 $1 / 98 \cdots$, 以此类推, 99 次失 败了, 第一百次肯定成功, 创新型的大学生一定要有 这样的信念。

当然, 不必要的风险是不能冒的, 模仿是创新的 第一步。教会学生善于模仿, 善于学习, 善于从模仿 中引申而不是抄袭, 就教会了学生创新的第一步。师 傅领进门, 修行在个人, 只要我们在大学里给学生灌 输了创新的思想, 教会了学生创新的方法, 加强了学 生创新的胆略, 那么, 这样的大学生走上了工作岗位 后必是创新型人才, 具备创业的潜质。

\section{致谢}

基金：2020 年国家级大学生创新训练项目 “互联 网+生态农业” 经营模式研究--侧重陕西贫困地区, 阶段性成果，S202010702015

\section{REFERENCES}

[1] Yang Jian. Li Zhi Qiang. Chen Huarong. Exploration on Cultivation of Professional Quality and Employment Ability of College Studentsin the New Era[J].Education and Teaching Forum2020,(27),236-237

[2] Dong Hai Lin. Cultivation of College Students' Innovation and Entrepreneurship Ability Based on Participatory Teaching[J]. Modern trade industry 2021,42(01),94-95

DOI:10.19311/j.cnki.1672-3198.2021.01.042 